\title{
The Effect of Fuel Injection Timing on the Combustion and Emission Characteristics of a Natural Gas Fueled Engine at Part Loads
}

\author{
Haeng-Muk $\mathrm{Cho}^{\dagger}$ \\ (Received August 25, 2008 ; Revised November 24, 2008 ; Accepted November 24, 2008)
}

\begin{abstract}
For a sequential port fuel injection natural gas engine, its combustion and emission characteristics at low loads are crucial to meet light duty vehicle emission regulations. Fuel injection timing is an important parameter related to the mixture formation in the cylinder. Its effect on the combustion and emission characteristics of a natural gas engine were investigated at $0.2 \mathrm{MPa}$ brake mean effective pressure (BMEP) $/ 2000 \mathrm{rpm}$ and $0.26 \mathrm{MPa} \mathrm{BMEP} / 1500 \mathrm{rpm}$. The results show that early fuel injection timing is beneficial to the reduction of the coefficient of variation (COV) of indicated mean effective pressure (IMEP) under lean burn conditions and to extending the lean burn limits at the given loads. When relative air/fuel ratio is over 1.3, fuel injection timing has a relatively large effect on engine out emissions. The levels of NOx emissions are more sensitive to the fuel injection timing at $0.26 \mathrm{MPa}$ BMEP/1500 rpm. An early fuel injection timing under lean burn conditions can be used to control engine out NOx emissions.
\end{abstract}

Key words : Natural gas, Emission, Lean burn, Combustion, Engine

\section{Introduction}

Natural gas can be used as a reliable and safe alternative fuel of internal combustion engines mainly due to its abundance and indigenous availability at attractive prices. Thanks to the low $\mathrm{H} / \mathrm{C}$ ratio of natural gas which is approximately in the range of 3.7 to $4.0^{[1]}$, the $\mathrm{CO}_{2}$ emissions from a natural gas engine can be reduced by more than 20 percent compared to a gasoline engine at the equal power ${ }^{[2]}$, and are even below those of diesel engines at the same air fuel ratio, while keeping almost the same thermal efficiency under very lean conditions ${ }^{[3]-[4]}$. On the other hand, natural gas has high research octane number. The antiknock properties of a lean burn natural gas engine are further improved. Therefore, a lean burn natural gas engine with high compression ratio can achieve high thermal efficiency, due to increased specific heat ratio, lower combustion temperature and reduced throttling loss ${ }^{[5]-[7]}$. By increasing the boost pressure levels, lean burn natural gas engines can produce higher power $^{[8]}$ and their full load thermal efficiencies can

\footnotetext{
† Corresponding Author(Division of Mechanical Engineering and Automotive Engineering, Kongju National Univeristy, 276, Budae Dong, Cheonan City, Chungnam 330-717, Korea. E-mail: hmcho@kongju.ac.kr. Tel: 041-521-9287)
} 
even approach their diesel engine counterparts $^{[9]}$.

Therefore, the objective of this study is to investigate the effect of fuel injection timings during the intake stroke on the combustion and emission characteristics of a port fuel injection natural gas engine at part loads and find a way to achieve stable combustion and low engine emissions at steady state operating conditions.

\section{Experimental apparatus and test procedure}

The engine used in this study was a modified four-stroke four cylinder port fuel injection spark ignition natural gas engine with a bore of $78.7 \mathrm{~mm}$, a stroke of $69 \mathrm{~mm}$ and a compression ratio of 9.3.

A Horiba MEXA-7100DEGR exhaust gas analyzer was used to measure total hydrocarbon (THC), $\mathrm{CO}$ and NOx emissions through a flame ionization detector (FID), a non-dispersive infrared analyzer (NDIR) and a chemiluminescent detector (CLD), respectively. THC, $\mathrm{CO}$ and $\mathrm{NOx}$ emissions were the average values of the acquired data in 60 seconds at each steady state operating condition. Fig. 1 shows the schematic of the experimental setup.

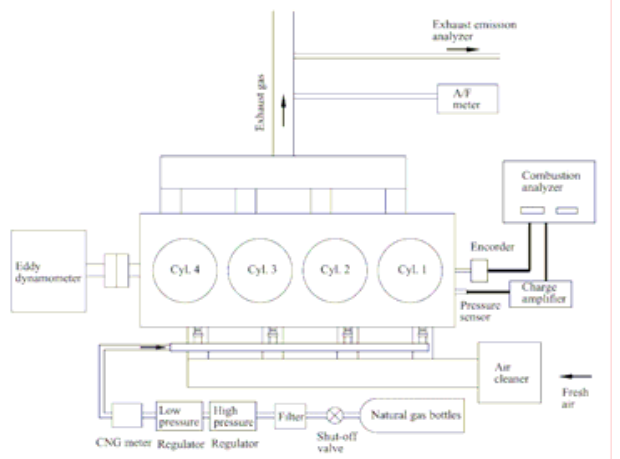

Fig. 1 The schematic of the experimental setup
The natural gas used was composed of 92.6\% methane, 5.8\% ethane, $1.2 \%$ carbon dioxide and $0.4 \%$ other components by volume.

\section{Results and discussion}

Based on the first law of thermodynamics, the rate of heat release can be calculated from the cylinder pressure. The ignition timing (CA10) is indicated by the crank angle at which 10 percent of the fuel is burned. The main combustion period (CA90) is defined as the 10-90 percent mass fraction fuel burn duration.

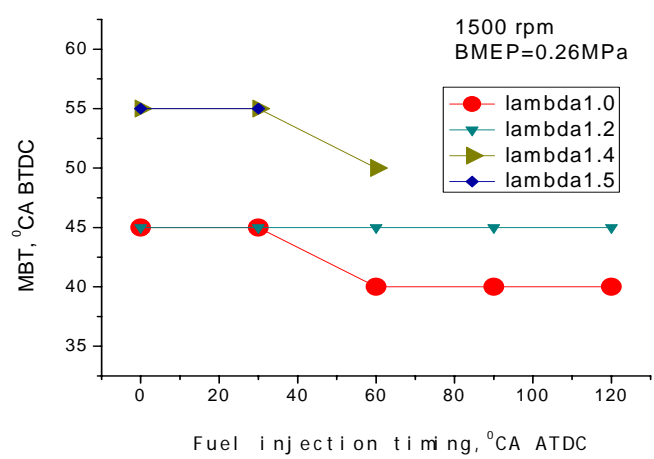

Fig. 2 The MBT timings at different fuel injection timings

Fig.2 is found that fuel injection timing has a slight effect on the MBT timing. But the overall air fuel ratio in the cylinder affects the MBT timing much more at different loads. When lambda increases at a given load, the MBT timing advances since the time required for the initial flame development and the period for rapid flame development increases.

Fig. 3 shows the effect of fuel injection timing. At $0.26 \mathrm{MPa} \mathrm{BMEP} / 1500 \mathrm{rpm}$, CA10 has much more changes with fuel injection timing.

Late CA10 at lambda $=0.9$ causes the main combustion duration to occur in the expansion stroke, hence, CA10 prolongs. 
The similar trend of combustion duration with fuel injection timing is observed at $0.26 \mathrm{MPa}$ BMEP/1500 rpm.

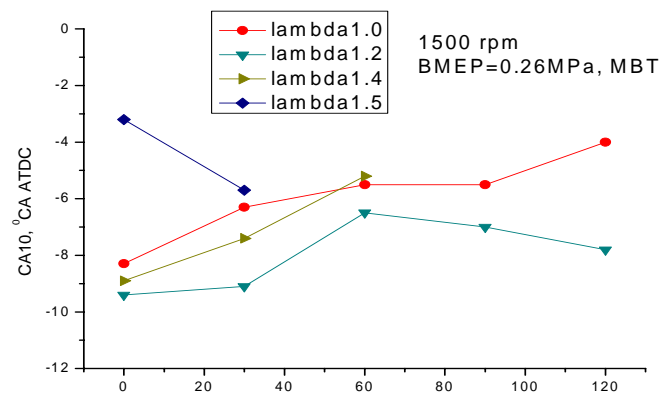

Fuel injection ti mi ng, ${ }^{\circ} \mathrm{CA}$ ATDC

Fig. 3 The effect of fuel injection timing on CA10 at the MBT timings

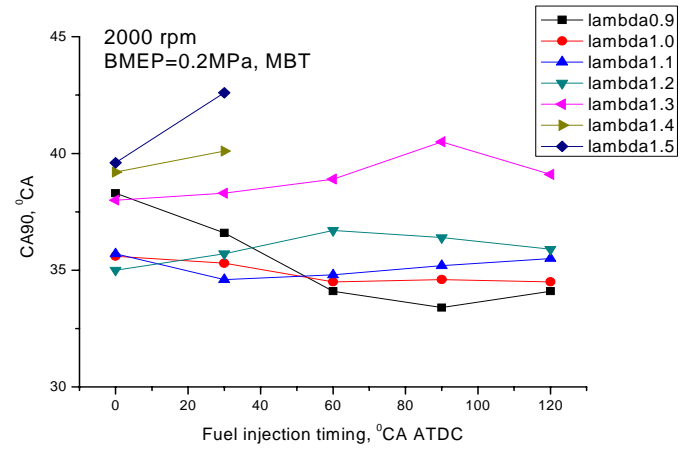

Fig. 4 The effect of fuel injection timing on CA90 at the MBT timings

It is also shown in Fig. 4 that the combustion duration changes slightly with fuel injection timing. Since the fuel injection width decreases with lambda at a given load, the time available to prepare mixture before spark discharge is increased when lambda is greater than 1.3 and is shortened at lambda $=0.9$. This indicates that fuel injection timing influences the mixture formation in the cylinder, and it changes the occurrence of ignition and burning rate. Hence, combustion duration is prolonged at relatively rich or much leaner cases.

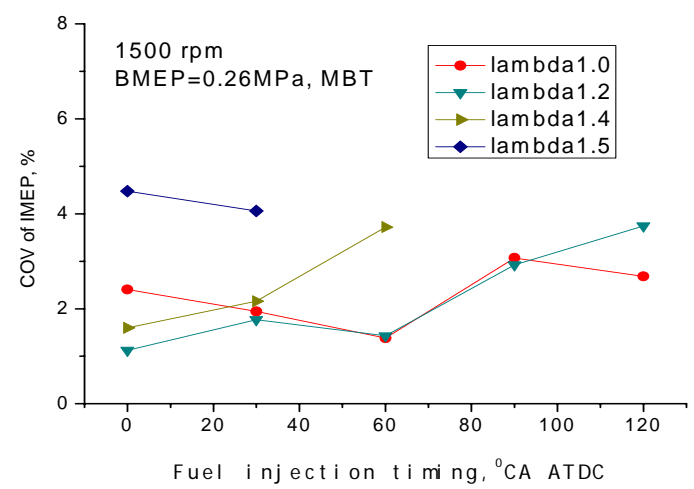

Fig. 5 The effect of fuel injection timing on the COV of IMEP at the MBT timings

Fig. 5 illustrates the relationship between fuel injection timing and the $\mathrm{COV}$ of IMEP under different operating conditions. When the engine load is 0.26 $\mathrm{MPa} \mathrm{BMEP} / 1500 \mathrm{rpm}$, the COV of IMEP increases more with delayed fuel injection timing at a given lambda. Since a high engine speed increases the turbulence intensity in the cylinder, it is contributed to the reduction of the COV of IMEP at a high engine speed. In the meantime, the change of the COV of IMEP with fuel injection timing at $0.26 \mathrm{MPa} \mathrm{BMEP} / 1500$ $\mathrm{rpm}$ is higher. It means that the $\mathrm{COV}$ of IMEP is susceptible to the fuel injection timings at low engine speed. Therefore, the COV of IMEP increases with delayed fuel injection timing. Independent of engine loads at a fuel injection timing, the amount of fuel in the cylinder decreases with increasing lambda, and the burning rate of the mixture decreases and, finally, the COV of IMEP increases. However, the COV of IMEP increases much more with a delay of fuel injection timing at lean burn conditions. Since the change in fuel injection timing may alter the direction or the intensity of the bulk 
flow, late fuel injection timing indicates that there is insufficient time to mix air and natural gas in the cylinder, more heterogeneous mixture around the spark plug at the time of spark discharge may influence the flame development. Fig. 6 shows the engine-out THC emissions at different operating conditions. Independent of the engine loads, THC emissions decrease and then increase again when lambda increases at a fixed fuel injection timing. The fuel injection timing has a slight effect on the THC emissions when lambda is in the range 1.0 to 1.3. The boundary layer quenching in the cylinder is decreased with fuel injection timing since fuel has less time to contact cylinder walls.

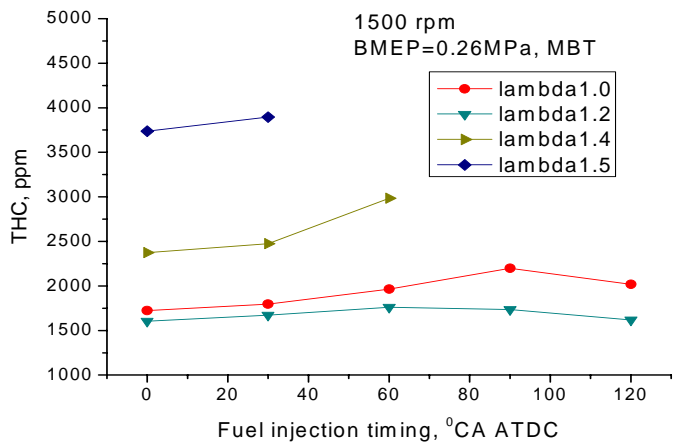

Fig. 6 The effect of fuel injection timing on THC emissions at the MBT timings

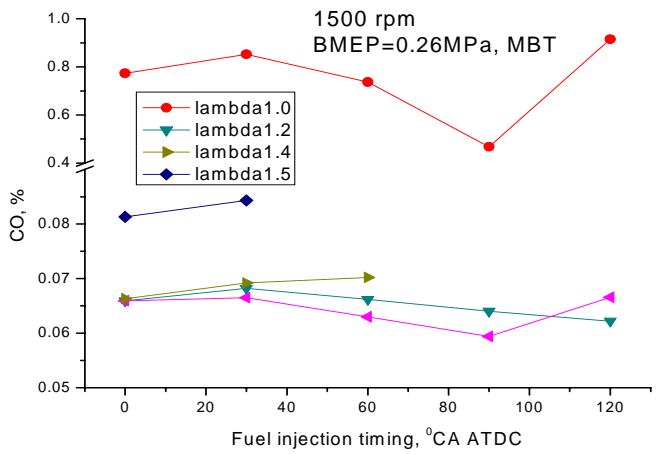

Fig. 7 The effect of fuel injection timing on CO emissions at the MBT timings
It is also shown that at $0.2 \mathrm{MPa}$ BMEP/1500 rpm, the THC emissions increase with delayed fuel injection timing at lambda $=0.9$ and the THC emissions are higher than those when lambda is between 1.0 and 1.3 since there is less air in the cylinder in the former case. On the other hand, late fuel injection indicates that fuel has less time to mix, which is contributed to the increase of unburned hydrocarbon emissions.

Fig. 7 shows the trend of engine-out $\mathrm{CO}$ emissions with fuel injection timing under different operating conditions. When lambda is higher than 1.0, CO emissions are controlled by the fuel/air equivalence ratio and lean mixture is attributed to the reduction of $\mathrm{CO}$ emissions. However, when lambda is over 1.3, the COV of IMEP increases, the mixture can not burn completely and $\mathrm{CO}$ emissions increase. The similar trend of $\mathrm{CO}$ emissions is found at $0.26 \mathrm{MPa} \mathrm{BMEP} / 1500 \mathrm{rpm}$.

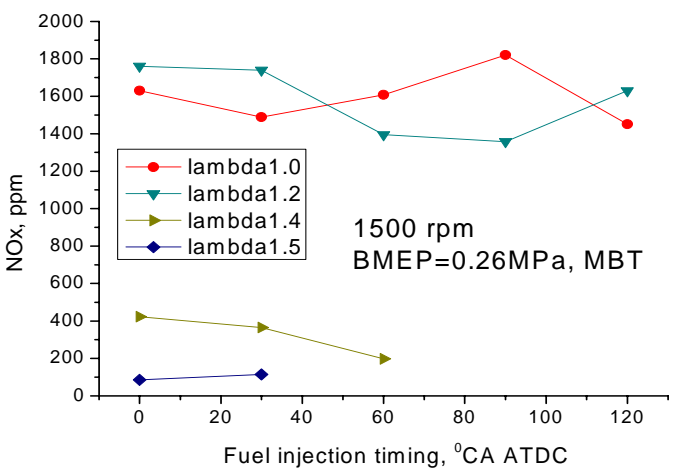

Fig. 8 The effect of fuel injection timing on NOx emissions at the MBT timings

Fig. 8 shows the effect of fuel injection timing on NOx emissions under different operating conditions. As expected, NOx emissions reach their peak values at about lambda=1.1, while NOx emissions sharply decrease when lambda further increases. Low combustion temperatures 
at leaner conditions contribute to the reduction of engine-out NOx emissions.

It is also shown that fuel injection timing has a different effect on NOx emissions at various lambdas. When lambda is in the range 1.1 to 1.3 , the lowest NOx emissions occur at $60^{\circ}$ and $90^{\circ}$ CA ATDC fuel injection timing at the two loads. It means that fuel injection timing can be used to control NOx emissions in some cases. Furthermore, NOx emissions are much affected by fuel injection timing at $0.26 \mathrm{MPa} \quad \mathrm{BMEP} / 1500 \mathrm{rpm}$ when lambda is in the range 1.0 to 1.2 . Since fuel injection duration is longer at 1500 rpm engine speed and turbulence intensity is relatively low, the mixture in the former is more heterogeneous, high NOx emissions yield in these regions where the mixture is close to the stroichiometry.

\section{Conclusions}

The combustion and emission characteristics of a natural gas engine under various operating conditions were investigated and the main conclusions are drawn as follows:

MBT has relationship to lambda and fuel injection timing. The MBT timing is early under lean conditions. But fuel injection timing has a slight effect on the MBT timing.

CA10 is affected by lambda, fuel injection timing and engine load. CA10 advances with fuel injection timing at rich mixture conditions. But it changes little at high engine speed and lean burn conditions, while CA10 occurs late with delaying fuel injection timing at low engine speed. Moreover, the main combustion duration at low engine speed is much more influenced by the fuel injection timing. Fuel injection timing has a slight effect on engine-out THC and CO emissions in most cases. But its effect on engine-out NOx emissions is much higher at low engine speed.

\section{Acknowledgements}

This work was supported by the Korea Foundation for International Cooperation of Science \&Technology(KICOS) through a grant provided by the Korean Ministry of Science \&Technology(MOST) in 2008 (No. 2008-0069).

\section{References}

[1] P. Einewall, P. Tunestål and B. Johansson, Lean burn natural gas operation vs. stoichiometric operation with EGR and a three way catalyst, Society of Automotive Engineers, USA (2005) 2005-01-0250.

[2] T. Kato, K. Saeki, H. Nishide and T. Yamada, Development of CNG fueled engine with lean burn for small size commercial van, JSAE Review 22 (2001) 365-368.

[3] P. L. Mtui and P. G. Hill, Ignition delay and combustion duration with natural gas fueling of diesel engines, Society of Automotive Engineers, USA (1996) 961933.

[4] R. Tilagone, G. Monnier, A. Chaouche, Y. Baguelin and S. De Chauveron, Development of a high efficiency, low emission SI-CNG bus engine, Society 
of Automotive Engineers, USA (1996) 961080.

[5] P. Corbo, M. Gambino, S. Iannaccone and A. Unich, Comparison between lean-burn and stoichiometric technologies for CNG heavy-duty engines, Society of Automotive Engineers, USA (1995) 950057.

[6] A. Das and H. C. Watson, Development of a natural gas spark ignition engine for optimum performance, Proc. Inst. Mech. Eng., Part D: J Automob. Eng. 21 (1997) 361-78.

[7] A. Manivannan, P. P. Tamil, S. Chandrasekan and R. Ramprabhu, Lean burn natural gas spark ignition engine - An overview. Society of Automotive Engineers, USA (2003) 2003-01-0638.

[8] L. H. Borges, C. Hollnagel and W. Muraro, Development of a MercedesBenz natural gas engine M366LAG with a lean-burn combustion system. Society of Automotive Engineers, USA (1996) 962378.

[9] T. Yamato, H. Sekino, T. Ninomiya and M. Hayashida, Stratification of incylinder mixture distributions by tuned port injection in a 4-valve SI gas engine, Society of Automotive Engineers, USA (2001) 2001-01-0610.

\section{Author Profile}

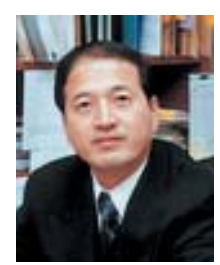

Haeng-Muk Cho

Date of birth: Nov. 27. 1960. Young University, 1978 to 1982. Bachelor of Mechanical Engineering. Yonsei University, 1987 to 1990, Master of Environment Automotive Engineering. Hanyang University, 1991 to 1997, Doctor of Mechanical Engineering (Internal Combustion Engines). Hyundai Motor Company, 1984 to 1993, Automotive Engineer. Loughborough University (UK), 1997 to 1998, Post Doctor. Tsing-Hwa University (China), 2002 to 2003, Visiting Prof. Kongju National University, 1999 to present, Associate Prof. 